\title{
Resected case of stage IV pleomorphic carcinoma of the lung with long-term survival
}

\author{
Haruki Choshi ${ }^{1}$, Mototsugu Watanabe ${ }^{1 *}$, Hiroyuki Ujike ${ }^{1}$, Yumiko Sato ${ }^{2}$, Toshiaki Morito ${ }^{2}$, Ryujiro Sugimoto ${ }^{3}$ and \\ Kazuhiko Kataoka ${ }^{1}$
}

\begin{abstract}
Background: No established treatments for pulmonary pleomorphic carcinoma exist because of its rarity, and the prognosis is poorer than that of other non-small cell lung cancers.

Case report: We present a case of stage IV pleomorphic carcinoma; the patient was a 66-year-old male. He was referred to our hospital because of a right adrenal hemorrhage and a lung tumor. A systemic examination revealed that the lung tumor was a primary lung cancer and that the adrenal hemorrhage was due to a metastatic cancer. We performed an adrenalectomy and resection of the lung tumor and obtained a diagnosis of pleomorphic carcinoma with adrenal metastasis. The patient has remained recurrence-free for 6 years since the surgery.

Conclusions: We report a patient with stage IV pleomorphic carcinoma of the lung and an oligometastasis in whom a complete resection enabled a good outcome. Additional reports are needed to clarify definite prognostic factors and the optimal treatment for pleomorphic carcinoma.
\end{abstract}

Keywords: Pleomorphic carcinoma, Oligometastasis, Adrenal hemorrhage

\section{Background}

Pleomorphic carcinoma is a rare type of non-small cell lung cancer (NSCLC) that accounts for approximately $0.1-0.4 \%$ of primary lung tumors [1]. No established treatments exist because of its rarity; consequently, pleomorphic carcinoma is associated with a worse outcome than other NSCLC. In addition, the presence of distant metastases can worsen the prognosis [1-3]. Although the adrenal gland is a common organ for distant metastases of primary lung cancer [4], adrenal metastases are often asymptomatic. Adrenal hemorrhages are relative rare, can cause pain, and can worsen the prognosis because of circulatory failure, an adrenal crisis, or other events [5-8].

\footnotetext{
* Correspondence: mowatanabe@s.okayama-u.ac.jp

'Department of Thoracic Surgery, Iwakuni Clinical Center, 1-1-1 Atago-machi, Iwakuni-shi, Yamaguchi 740-8510, Japan

Full list of author information is available at the end of the article
}

In this report, we described a rare patient with pleomorphic carcinoma and adrenal hemorrhage who survived without any recurrences for more than 6 years after a complete resection.

\section{Case presentation}

A 66-year-old man was admitted to the clinic of a primary care doctor complaining of a sudden deterioration in right hypochondoralgia persisting for 2 weeks. A computed tomography (CT) scan revealed a right adrenal hemorrhage and an abnormal tumor in the upper lobe of his left lung. He was subsequently referred to our hospital for further examination and treatment.

His past medical history and family history were unremarkable. He was a current smoker with a history of 46 pack-years. An enhanced CT scan showed a massive shadow in the left lung S1 +2 progressing to S6 beyond the lung lobe, with a maximum diameter of about 42 mm (Fig. 1a), and a right adrenal hematoma with no

\section{Springer Open}

(c) The Author(s). 2020 Open Access This article is licensed under a Creative Commons Attribution 4.0 International License, which permits use, sharing, adaptation, distribution and reproduction in any medium or format, as long as you give appropriate credit to the original author(s) and the source, provide a link to the Creative Commons licence, and indicate if changes were made. The images or other third party material in this article are included in the article's Creative Commons licence, unless indicated otherwise in a credit line to the material. If material is not included in the article's Creative Commons licence and your intended use is not permitted by statutory regulation or exceeds the permitted use, you will need to obtain permission directly from the copyright holder. To view a copy of this licence, visit http://creativecommons.org/licenses/by/4.0/. 


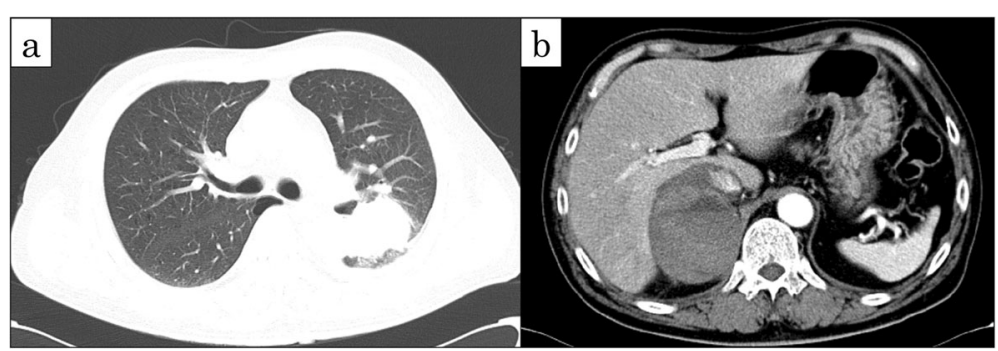

Fig. 1 CT scan showed abnormal masses. a Chest CT scan showed a 42-mm tumor in the left lung S1 + 2 progressing to S6. b Abdominal enhanced CT scan showed a 82-mm mass with no active bleeding

active bleeding (Fig. 1b). The laboratory data revealed a slight elevation in carcinoembryonic antigen (CEA, 5.6 $\mathrm{ng} / \mathrm{mL}$ ) and neuron-specific enolase (NSE, $18.52 \mathrm{ng} / \mathrm{mL}$ ). The patient had mild anemia (hemoglobin, $10.3 \mathrm{~g} / \mathrm{dL}$ ).

A diagnosis of the pulmonary lesion using a bronchoscopic trans-bronchial lung biopsy showed no evidence of malignancy; therefore, a CT-guided percutaneous needle biopsy was performed. The pathological examination showed a non-small cell lung cancer (NSCLC) that was suspected to be a pleomorphic carcinoma. The adrenal lesion was diagnosed as a nonfunctional tumor based on endocrine examinations and adrenal medulla scintigraphy $\left({ }^{123} \mathrm{I}-\mathrm{MIBG}\right) .18-$ Fluorodeoxyglucose positron emission tomography (FDGPET) showed the accumulation of FDG not only in the left lung nodule (SUVmax, 17.0) (Fig. 2a) but also in the right adrenal one (SUVmax, 4.1) (Fig. 2b). Together, these results suggested a diagnosis of NSCLC and adrenal metastasis, and the clinical stage was classified as cT2bNOM1b, stage IV (TNM classification 7th edition).

Because there was a risk of rebleeding from adrenal metastasis, we performed a right adrenalectomy. We considered that a complete resection of the primary lung cancer would be possible since the adrenal metastasis was an oligometastasis. A pathological analysis of the lung tumor demonstrated areas of atypical cells with eosinophilic cytoplasms as well as sarcomatous component, with extensive necrosis (Fig. 3a, b). Immunohistochemistry revealed that the tumor cells were positive for cytokeratin AE1/3, CAM5.2, CK7, and p63 (partial) but negative for 34ßE12, CK20, TTF-1, calretinin, and D2-40. The adrenal tumor was similar in pathologic and immunohistochemical analyses (Fig. 3c). Thus, the final diagnosis was pleomorphic carcinoma of the lung with an adrenal metastasis, pT2bNOM1b, stage IV (TNM classification 7th edition).

The patient received chemotherapy as stage IV NSCLC $\left(60 \mathrm{mg} / \mathrm{m}^{2}\right.$ of cisplatin on day 1 and $40 \mathrm{mg} / \mathrm{m}^{2}$ of TS- 1 twice a day on days 1 to 14 , repeated every 4 weeks). After two courses, he decided to quit the intravenous chemotherapy because of adverse events, general malaise, and anorexia. We suggested to receive oral chemotherapy, but he refused to take TS- 1 because he feared adverse events. Consequently, he began taking UFT $(600 \mathrm{mg} /$ day) and continued this treatment for 2 years. He has survived without any recurrences for 6 years since the surgery.

\section{Discussion}

Pleomorphic carcinoma is a rare type of NSCLC and has been reported to account for 0.1 to $0.4 \%$ of primary lung tumors [1]. The mean age at diagnosis was 60 to 65 years. The male to female ratio is $2.1: 1$, and 60 to $90 \%$ of all patients are smokers. Because the upper lobe is more frequently in contact with cigarette smoke, the upper lobe (48-69\%), particularly the right upper lobe (33$50 \%)$, is the most common site $[1,9,10]$.

In the 2015 World Health Organization (WHO) histologic classification of lung tumors, pleomorphic carcinoma was classified as a subtype of sarcomatoid carcinoma. Sarcomatoid carcinoma is grouped into pleomorphic carcinoma, spindle cell carcinoma, giant cell

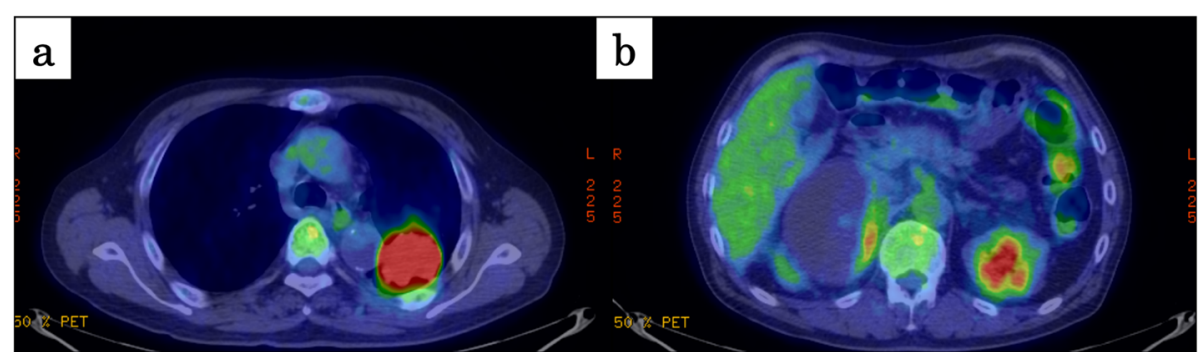

Fig. 2 Imaging of FDG-PET. a There was high accumulation of FDG at the left lung tumor (SUVmax, 17.0). b There was slightly accumulation of FDG at the edge of abdominal tumor (SUVmax, 4.1) 


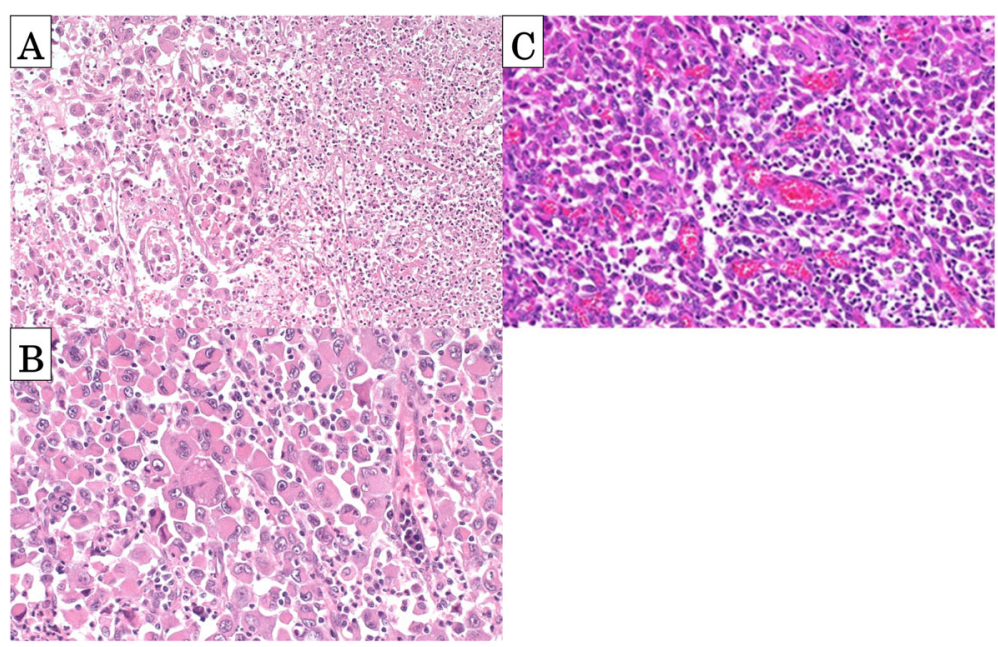

Fig. 3 The pathologic analysis. a, b Pathologic analysis of the lung tumor revealed atypical giant cells with eosinophilic cytoplasms as well as sarcomatous component with necrosis. c Pathologic analysis of the adrenal tumor revealed similar histologic appearance to lung tumor

carcinoma, carcinosarcoma, and pulmonary blastoma. A diagnosis of pleomorphic carcinoma cannot be made without a complete evaluation of the entire tumor histologically. Pleomorphic carcinoma consists of poorly differentiated adenocarcinoma, squamous cell carcinoma, or large cell carcinoma containing at least $10 \%$ spindle and/or giant cells or a carcinoma comprised only of spindle and giant cells [11]. For tumors containing a wide range of cellular components, pleomorphic carcinoma is the most common subtype of sarcomatoid carcinomas [12].

In general, patients with pleomorphic carcinoma received same treatment with other NSCLCs. However, an effective chemotherapy for pleomorphic carcinoma has not been established because of the insufficient data on pleomorphic carcinoma, particularly a lack of long-term follow-up data. Previous studies reported that the overall survival rate was worse than those of other NSCLCs, with 1- and 5-year values of $45.5 \%$ and $20.1 \%$, respectively. The reported prognostic factors were tumor size $(>5-7 \mathrm{~cm})$, presence of distant or lymph node metastasis, and a clinical stage of $>\mathrm{I}$, among which lymph node metastasis has attracted attention [12-16]. Stage IV pleomorphic carcinoma typically contains most of these factors, resulting in a remarkably low 5-year survival rate. Most studies focused on lymph node metastases have compared $\mathrm{pN} 0$ and $\mathrm{pN} 2$ without distant metastasis [16-18]; thus, the prognostic factors for stage IV pleomorphic carcinoma have not been studied.

However, there are some reports of stage IV pleomorphic carcinoma cases obtaining long-term survival after resections. To our knowledge, five cases have been reported, and the features of these cases are shown in Table 1 [1, 3, 19-21]. None of these cases had lymph node metastasis. The cases shown in Table 1 suggest that patients with limited distant metastasis can obtain better outcomes after a complete primary lung tumor resection with metastasectomy if they do not have lymph

Table 1 The features of stage IV pleomorphic carcinoma cases getting long-term survival after resections

\begin{tabular}{|c|c|c|c|c|c|c|}
\hline & Case 1 & Case 2 & Case 3 & Case 4 & Case 5 & Case 6 \\
\hline Age & 71 & 48 & 63 & 69 & 62 & 66 \\
\hline Sex & Male & Male & Male & Male & Male & Male \\
\hline Primary lesion & Right lower lobe & Right upper lobe & Left upper lobe & Right upper lobe & Left upper lobe & Left upper lobe \\
\hline Size $(m m)$ & 70 & 65 & 73 & 48 & 33 & 42 \\
\hline Metastasis lesion & Brain & Jejunum & Small bowel & Stomach & Stomach & Right adrenal grand \\
\hline Lymph node metastasis & No & No & No & No & No & No \\
\hline \multirow[t]{3}{*}{ Chemotherapy } & Induction & No & Adjuvant & No & No & Adjuvant \\
\hline & $\mathrm{CBDCA}+\mathrm{GEM}$ & & $\mathrm{CBDCA}+\mathrm{GEM}$ & & & $\mathrm{CDDP}+\mathrm{S}-1$ \\
\hline & 6 courses & & & & & $\rightarrow$ UFT \\
\hline Recurrence-free time (year) & 7 & 6 & 1 & 5 & 4 & 6 \\
\hline
\end{tabular}


node metastasis. Complete resection may contribute to the long-term survival of patients with stage IV pleomorphic carcinoma. In addition, Yokoyama et al. reported that the presence of tumor spread through air spaces (STAS) was a useful prognostic factor among cases of surgically resected lung pleomorphic carcinoma [22]. Most cases in the recent report were of stages other than stage IV because all the cases had undergone resection. Further studies in stage IV patients are needed. In our case, the adrenal gland was the only site of metastasis, and no lymph node metastasis was seen; consequently, we were able to perform a complete resection and to obtain long-term survival.

In addition to the progression of cancer itself, our case experienced an adrenal hemorrhage secondary to the adrenal metastasis, which is associated with a high mortality rate. In general, most adrenal metastases are asymptomatic and are often detected incidentally by CT scan. Almost $40 \%$ of NSCLC patients develop adrenal metastases $[6,7,23]$. An analysis adjusted according to blood flow distribution reported that lung cancer metastasized to the adrenal gland most frequently [4]. In contrast, adrenal metastases-related hemorrhages are rare in patients with primary lung cancer and cause acute pain. To our knowledge, only 30 cases have been reported worldwide, including the present case [5-8]. Among the clinical features, 28 cases experienced pain, 18 cases had anemia, and 10 cases had nausea or vomiting. Regarding the pathological diagnosis of the primary lung cancer, many cases were adenocarcinoma $(n=12)$, followed by large cell carcinoma $(n=$ $7)$ and pleomorphic carcinoma $(n=3,10 \%)$. The prognosis of adrenal metastasis-related hemorrhage is poor. Survival for more than 1 year has only been confirmed in three cases. The most common cause of death was hemorrhage $(n=10)$, followed by cancer progression $(n=$ $4)$ and infection $(n=3)[6,8]$. The control of these factors can allow long-term survival for patients with adrenal hemorrhages. In our case, the adrenal lesion was a hematoma with no active bleeding. Because there was a risk of rebleeding, we performed a right adrenalectomy to control the disease. Additionally, the resection of the primary site was considered optimal, as described above. We performed a complete resection for our case, and the patient obtained a long-term survival.

Our case suggests that a complete resection can enable long-term survival in patients with stage IV pleomorphic carcinoma and adrenal hemorrhage. Because few stage IV cases with long-term follow-up have been reported, further cases should be gathered and examined to establish an optimal treatment for pleomorphic carcinoma.

\section{Conclusion}

We report a rare case of pleomorphic carcinoma that was discovered incidentally to adrenal bleeding; surgery was possible, and long-term survival was obtained. Complete resection may enable a good outcome in patients with stage IV pleomorphic carcinoma of the lung with adrenal hemorrhage secondary to adrenal metastasis. Further studies are warranted to provide prognostic factors and surgical benefits for this poor prognostic disease.

\section{Abbreviations}

NSCLC: Non-small cell lung cancer; CT: Computed tomography; CEA: Carcinoembryonic antigen; NSE: Neuron-specific enolase; FDG-PET: 18Fluorodeoxyglucose positron emission tomography; WHO: World Health Organization; STAS: Spread through air spaces

\section{Acknowledgements}

Not applicable

\section{Authors' contributions}

$\mathrm{HC}$ wrote the original draft. MW, HU, RS, and KK reviewed and edited the manuscript. YS and TM contributed to supervision. All authors read and approved the final manuscript.

\section{Funding}

Not applicable

Availability of data and materials

Not applicable

Ethics approval and consent to participate

Not applicable

\section{Consent for publication}

Informed consent from the patient for the publication of this case report was obtained.

\section{Competing interests}

The authors have declared that no competing interests exist.

\section{Author details}

1Department of Thoracic Surgery, Iwakuni Clinical Center, 1-1-1 Atago-machi, Iwakuni-shi, Yamaguchi 740-8510, Japan. ${ }^{2}$ Department of Diagnostic Pathology, Iwakuni Clinical Center, Yamaguchi, Japan. ${ }^{3}$ Department of Cardiovascular and Thoracic Surgery, Ehime University Graduate School of Medicine, 454 Shitsukawa, Touon-shi, Ehime, Japan.

Received: 5 April 2020 Accepted: 10 May 2020

Published online: 24 May 2020

References

1. Zhang $X$, Wang $Y$, Zhao $L$, Jing $H$, Sang $S$, Du J. Pulmonary pleomorphic carcinoma: a case report and review of the literature. Medicine (Baltimore). 2017;96(29):e7465.

2. Yamanashi K, Marumo S, Miura K, Kawashima M. Long-term survival in a case of pleomorphic carcinoma with a brain metastasis. Case reports in oncology. 2014;7(3):799-803.

3. Nakai A, Suzuki K, Furuse H, Tsuda T, Masaki Y, Shinno H, et al. Multiple metastasizing pleomorphic adenomas of the lung. Intern Med. 2017;56(6): 691-4.

4. Harada T, Kawakami M, Ujita M, Saito Y, Odaka M, Sato S, et al. Analysis of metastasis in primary lung cancer (second report). Jpn Tokyo Jikeikai Med J. 2006:121:223-40.

5. Han H, Qiao P, Jiang XW, Wang B, Zhang XD. Acute flank abdominal pain as the chief complaint of spontaneous adrenal hemorrhage secondary to metastatic lung cancer. Urol Case Rep. 2018:16:65-8.

6. Wang J, Packer CD. Acute abdominal pain after intercourse: adrenal hemorrhage as the first sign of metastatic lung cancer. Case Rep Med. 2014; 2014:612036.

7. Sahasrabudhe N, Byers R. Massive haemorrhagic adrenal metastases leading to sudden death: a case report. BMJ Case Rep. 2009;2009. 
8. Tamura K, Furuse H, Sugiyama T, Kato T, Suzuki T, Kai F, et al. Bilateral adrenal hemorrhage due to adrenal metastasis of lung cancer. Nihon Hinyokika Gakkai Zasshi. 2013;104(1):17-21.

9. Fishback NF, Travis WD, Moran CA, Guinee DGJ, McCarthy WF, Koss MN Pleomorphic (spindle/giant cell) carcinoma of the lung. A clinicopathologic correlation of 78 cases. Cancer. 1994;73(12):2936-45.

10. Okuda M, Chang S, Nakano J, Misaki N, Ishikawa S, Yamamoto Y, et al. A review of 6 resected cases of pleomorphic carcinoma. Jpn J Chest Surg. 2008;22(5):736-40.

11. Travis WD, Brambilla E, Nicholson AG, Yatabe Y, Austin JHM, Beasley MB, et al. The 2015 World Health Organization classification of lung tumors: impact of genetic, clinical and radiologic advances since the 2004 classification. Journal of thoracic oncology : official publication of the International Association for the Study of Lung Cancer. 2015;10(9):1243-60

12. Sim JK, Chung SM, Choi JH, Oh JY, Lee SH, Kim JH, et al. Clinical and molecular characteristics of pulmonary sarcomatoid carcinoma. Korean J Intern Med. 2018;33(4):737-44.

13. Huang SY, Shen SJ, Li XY. Pulmonary sarcomatoid carcinoma: a clinicopathologic study and prognostic analysis of 51 cases. World I Surg Oncol. 2013.

14. Arshad HS, Dudekula RA, Niazi M, Malik S, Khaja M. A rare case of sarcomatoid carcinoma of the lung with spine metastasis, including a literature review. Am J Case Rep. 2017;18:760-5.

15. Hountis $\mathrm{P}$, Moraitis $\mathrm{S}$, Dedeilias $\mathrm{P}$, Ikonomidis $\mathrm{P}$, Douzinas M. Sarcomatoid lung carcinomas: a case series. Cases J. 2009;2:7900.

16. Hamatake D, Miyahara S, Yoshida Y, Hamanaka W, Katou H, Yanagisawa J, et al. Assessment of twenty-five cases of resected pleomorphic carcinoma. Jpn J Chest Surg. 2010;24(2):156-61.

17. Kayawake H, Okumura N, Nakashima T, Matsuoka T, Kameyama K. A clinical analysis of 27 surgically resected cases of pulmonary pleomorphic carcinoma. Jpn J Chest Surg. 2016;30(6):658-63.

18. Muto J, Otake S, Umemoto K, Suzuki T, Ono K. A study of surgical resection for pleomorphic carcinoma of the lung. Jpn J Jpn Surg. 2015;76(7):1549-52.

19. Miura N, Mori R, Takenaka T, Yamazaki K, Momosaki S, Takeo S. Stage IV pleomorphic carcinoma of the lung without recurrence for 6 years: a case report. Surg Case Rep. 2017;3(1):36.

20. Kim MJ, Lee HN, Kim JI, Kim GY. Pleomorphic carcinoma of the lung mimicking synchronous pulmonary adenocarcinoma and small bowel sarcoma. Ann Thorac Med. 2018;13(4):251-3.

21. Aokage K, Yoshida J, Ishii G, Takahashi S, Sugito M, Nishimura M, et al. Longterm survival in two cases of resected gastric metastasis of pulmonary pleomorphic carcinoma. Journal of thoracic oncology : official publication of the International Association for the Study of Lung Cancer. 2008;3(7):796-9

22. Yokoyama S, Murakami T, Tao H, Onoda H, Hara A, Miyazaki R, et al. Tumor spread through air spaces identifies a distinct subgroup with poor prognosis in surgically resected lung pleomorphic carcinoma. Chest. 2018; 154(4):838-47.

23. Fujii Y, Ohara K, Hamada M, Matukizono K, Tomiyama Y, Koreeda Y, et al. Adrenal hemorrhage resulting from bilateral adrenal metastasis of lung cancer: A case report. Jpn Ann Resp Sci. 2013;2(4):442-5.

\section{Publisher's Note}

Springer Nature remains neutral with regard to jurisdictional claims in published maps and institutional affiliations.

\section{Submit your manuscript to a SpringerOpen ${ }^{\circ}$ journal and benefit from:}

- Convenient online submission

- Rigorous peer review

- Open access: articles freely available online

High visibility within the field

- Retaining the copyright to your article

Submit your next manuscript at $\boldsymbol{\nabla}$ springeropen.com 